\title{
Numerical investigation on the cluster effect of an array of axial flow fans for air-cooled condensers in a power plant
}

\author{
YANG LiJun*, DU XiaoZe, ZHANG Hui \& YANG YongPing \\ Key Laboratory of Condition Monitoring and Control for Power Plant Equipment of Ministry of Education, School of Energy Power and Mecha- \\ nical Engineering, North China Electric Power University, Beijing 102206, China
}

Received August 15, 2010; accepted April 13, 2011

\begin{abstract}
The aerodynamic behavior of tens of axial flow fans incorporated with air-cooled condensers in a power plant is different from that of an individual fan. Investigation of the aerodynamic characteristics of axial flow fan array benefits its design optimization and running regulation. Based on a representative $2 \times 600 \mathrm{MW}$ direct-dry cooling power plant, the flow rate of each fan and the overall flow rate of the fan array are obtained in the absence of ambient wind and at various wind speeds and directions, using CFD simulation. The cluster factor of each fan and the average cluster factor of the fan array are calculated and analyzed. Results show that the cluster factors are different from each other and that the cluster effect with ambient wind is significantly different from the cluster effect with no wind. The fan at the periphery of the array or upwind of the ambient wind generally has a small cluster factor. The average cluster factor of the array decreases with the increasing wind speeds and also varies widely with wind direction. The cluster effect of the axial flow fan array can be applied to optimize the design and operation of air-cooled condensers in a power plant.
\end{abstract}

air-cooled condenser, axial flow fan, cluster effect, cluster factor, wind speed and direction

Citation: Yang L J, Du X Z, Zhang H, et al. Numerical investigation on the cluster effect of an array of axial flow fans for air-cooled condensers in a power plant. Chinese Sci Bull, 2011, 56: 2272-2280, doi: 10.1007/s11434-011-4524-x

An increased focus on water conservation has combined with continued concern over the environmental effects of both once-through and evaporative cooling, resulting in increased popularity of dry cooling technology. In particular, the use of air-cooled condenser (ACCs) in power plants for condenser heat rejection is expected to increase [1]. Largescale, air-cooled condensers in a power plant consists of an array of the condenser cells. For each condenser cell, the finned tube bundles are arranged in the form of an A-frame fitted with an axial flow fan below. Ambient air is impelled by the fans to flow through the finned tube bundles and the thermal duty of the exhaust steam from the turbine is removed in the air-cooled condensers. Many studies have found that finned tube bundles and axial flow fans work poorly in a wide range of specific climates, especially with large wind speeds and adverse wind directions.

*Corresponding author (email: yanglj@ncepu.edu.cn)
Meyer and Kroger [2] developed a numerical model to simulate the effect of an axial flow fan on the velocity field in the vicinity of the fan blades. In this model, the axial flow fan is regarded as an actuator disc. By using the actuator disc fan model, Meyer [3] numerically studied the effect of inlet flow distortions and found that inlet flow losses of the periphery fan are dominated by flow separation around the inlet lip of the fan inlet section. These flow losses can be reduced by the installation of a walkway at the edge of the fan platform or by removal of the periphery fan inlet section. Hotchkiss et al. [4] used computational fluid dynamics (CFD) methods to investigate the effects of ambient wind cross flows on the performance of axial flow fans in air-cooled condensers. van Rooyen and Kroger [5] studied the air flow around and through certain air-cooled condensers, assessing the performance of the fan with the actuator disc model. Bredell et al. [6] also used the actuator disc fan model to simulate the effect of fans in the flow domain of 
air-cooled condensers, and concluded that the distorted inlet flow conditions of fans can cause azimuthal variation in fan blade bending moments. Coetzee and du Toit [7] used blade element theory to determine the torque and thrust exerted on the air by fan blades, and investigated the influence of end-effects on flow fields in the vicinity of the heat exchanger. Meyer and Kroger [8] studied the aerodynamic behavior of a air-cooled heat exchanger plenum chamber for different fan performances, using CFD simulation. Bredell et al. [9] numerically investigated the effect of inlet flow distortions on the flow rate through the fans, and considered the volumetric effectiveness of two different types of axial flow fans at different platform heights. Their results also showed that the addition of a walkway can significantly increase the flow rate through the fans near the edge of the fan platform. Duvenhage and Kroger [10] investigated the influence of wind on fan performance and cooling air recirculation in an air-cooled condenser bank, concluding that cross wind significantly reduces the air flow rate in the upwind condenser cells, and that the wind along the longitudinal axis cause increased hot plume air recirculation. Duvenhage et al. [11] numerically and experimentally studied fan performance in air-cooled condensers during inlet flow distortions. Salta and Kroger [12] experimentally investigated flow rate reduction in air-cooled condensers from distorted inlet air flows. Meyer and Kroger [13] experimentally investigated effects of different fan and heat exchanger characteristics as well as the plenum chamber geometry on flow losses of air-cooled condensers. Meyer and Kroger [14] empirically measured the influence of the air-cooled heat exchanger geometry on inlet air flow losses. An equation based on their experimental results was formulated that calculates the heat exchanger inlet flow losses. Wang et al. [15] investigated the overall flow and temperature fields of air in the power plant by CFD simulation, finding that wind effects and fan suction induces plume recirculation. Installation of a side board below or above the fan platform was suggested to avoid such recirculation.

The aforementioned research has shown that reduced axial flow fan performance is caused by the inlet flow distortions produced by ambient wind cross flows. Ambient wind can have adverse impacts on the fans and air-cooled condensers. In most of the studies, the turbine and boiler buildings of the power plant are neglected, so the impacts of these buildings on the inlet air flows of the axial flow fan array are not considered. Furthermore, the A-type plenum chamber of the condenser cell is commonly simplified as a cubic box. For air-cooled condensers with no ambient wind, the performance of the axial flow fan array is still not clearly recognized. In this paper, the cluster effect of the axial flow fan array used by air-cooled condensers in a representative $2 \times 600 \mathrm{MW}$ power plant is investigated, with no wind and for various wind speeds and directions. This investigation benefits the design and operation of axial flow fans for air-cooled condensers in a power plant.

\section{Computational models}

The thermal-flow characteristics of an array of A-frame heat exchangers and fans are essentially different from those of an individual condenser cell. A novel concept of cluster factor is proposed to describe the cluster effect of an array of axial flow fans in air-cooled condensers [16]. This factor is defined as the ratio of the volumetric flow rate of each fan in the axial flow fan array to that of an individual fan, as follows:

$$
\eta_{i}=\frac{Q_{v, i}}{Q_{v, \text { ind }}},
$$

where $Q_{v, i}$ is the volumetric flow rate of each fan in the axial flow fan array. $Q_{v \text {,ind }}$ is the volumetric flow rate of an individual fan while running independently. For all fans in the array, the average cluster factor $\eta_{m}$ is defined as

$$
\eta_{m}=\frac{\sum_{i=1}^{n} Q_{v, i}}{n Q_{v, \text { ind }}},
$$

where $n$ is the total number of fans in the array. It can be seen from eq. (1) that the cluster factor denotes the flow difference between one particular fan in the fan array and the independently running fan. The greater the flow difference, the greater the cluster effect of the fan. The average cluster factor is used to evaluate the whole cluster effect of all the axial flow fans, as expressed in eq. (2). This factor is a measure of the aerodynamic interaction among all the axial flow fans.

The typical axial flow fan used with air-cooled condensers in a power plant is schematically shown in Figure 1, which is manufactured by Baoding Huiyang Fan Plant, China. It consists of 6-8 fan blades and has a small hub-tip ratio. For the combined finned tube bundle and fan system, the flow and heat transfer through the finned tube surfaces should be solved simultaneously with the aerodynamic characteristics of the axial flow fans. This method is a

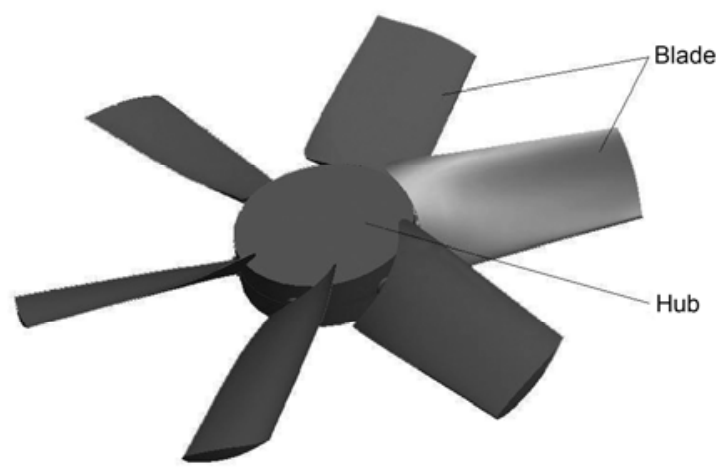

Figure 1 Schematic of axial flow fan used by air-cooled condensers in a power plant. 
possible alternative to an experimental investigation using commercially available CFD code to resolve the flow field through fans and thermal-flow fields through finned tube bundles. However, the flow complexities and geometrical modeling difficulties associated with the fan blade passages and finned tube bundles represent a great computational challenge [9]. Simplification of the fans and finned tube surfaces should be considered.

The fan model described in this paper is a lumped parameter model. It can be used to determine the impact of a fan with known characteristics upon some larger flow field. This model allows input of an empirical fan curve that governs the relationship between the head (pressure rise) and flow rate (velocity) across a fan element. The radial and tangential components of the fan swirl velocity can also be specified. The fan model does not provide an accurate description of the detailed flow through the fan blades. Rather, it predicts the amount of flow through the fan. For the combined finned tube bundle and fan system, the flow rate is determined by the balance between the losses in the bundle and the fan curve.

In the fan model, the fan is considered to be infinitesimally thin, and the discontinuous pressure rise $\Delta p$ across it is specified as a polynomial function of the axial velocity $v$ through the fan.

$$
\Delta p=\sum_{n=1}^{N} f_{n} v^{n-1},
$$

where $f_{n}$ is the polynomial coefficient. In terms of the performance curve of the typical fan used by air-cooled condensers, the polynomial coefficients are calculated and listed in Table 1.

Owing to the three-dimensional flow complexities caused by the fan blades, tangential and radial velocities are imposed on the fan surface to generate swirl. These velocities can be specified as functions of radial distance from the fan center. In this paper, the radial velocity is neglected. The tangential velocity component $U_{\theta}$ can be specified by the following equation:

$$
U_{\theta}=\sum_{n=-1}^{N} g_{n} r^{n},
$$

where $r$ is the radial distance from the fan center. $g_{n}$ is the polynomial coefficient. When the geometric parameters of the fan blade are known, the tangential velocity at different radial distances can be obtained. The polynomial coefficients that fit the tangential velocity are listed in Table 2.

Table 1 Polynomial coefficients that fit the performance curve of the axial flow fan

\begin{tabular}{ccccc}
\hline$f_{1}$ & $f_{2}$ & $f_{3}$ & $f_{4}$ & $f_{5}$ \\
\hline 195.59557 & -19.99838 & 3.96681 & -0.56975 & 0.0219 \\
\hline
\end{tabular}

Table 2 Polynomial coefficients that fit the tangential velocity of the axial flow fan

\begin{tabular}{ccccc}
\hline$g_{-1}$ & $g_{0}$ & $g_{1}$ & $g_{2}$ & $g_{3}$ \\
\hline-15.1 & 25.76 & -11.791 & 4.321 & -0.354 \\
\hline
\end{tabular}

The finned tube bundle of air-cooled condensers is simplified as a lumped-parameter radiator. In the radiator model, the pressure drop $\Delta p$ varies with the normal component of velocity $v$ through the finned tube bundle as follows:

$$
\Delta p=k_{L} \frac{1}{2} \rho v^{2},
$$

where $\rho$ is the air density and $K_{L}$ is the non-dimensional loss coefficient, which can be simplified as a polynomial function

$$
k_{L}=\sum_{n=1}^{N} r_{n} v^{n-1},
$$

where $r_{n}$ is the polynomial coefficient. For the widely adopted Single Row Condenser (SRC) design in power plants, the heat exchanger surface is generally the wavefinned flat-tube bundle. According to the flow loss experiment of cooling air through the wave-finned flat-tube bundle, the polynomial coefficients are obtained as shown in Table 3.

The heat flux $q$ from the radiator to the surrounding air is given as

$$
q=h\left(T_{s}-T_{a, d}\right)
$$

where $T_{s}$ is the condensing temperature of the exhaust steam. If the conductive thermal resistance through the wall and the condensation thermal resistance are neglected, the tube outer wall temperature can be regarded as $T_{s}$. $T_{a, d}$ is the air temperature downstream of the radiator. The convective heat transfer coefficient $h$ is normally specified as a polynomial function of the normal component of velocity:

$$
h=\sum_{n=1}^{N} h_{n} v^{n-1},
$$

where $h_{n}$ is the polynomial coefficient. These coefficients are given in Table 4 in terms of the experimental heat transfer data of cooling air in air-cooled condensers.

Table 3 Polynomial coefficients that fit the pressure drop of air flowing through the finned tube bundles

\begin{tabular}{ccc}
\hline$r_{1}$ & $r_{2}$ & $r_{3}$ \\
\hline 71.68881 & -31.70742 & 4.79819 \\
\hline
\end{tabular}

Table 4 Polynomial coefficients that fit the experimental heat transfer data of air

\begin{tabular}{ccc}
\hline$h_{1}$ & $h_{2}$ & $h_{3}$ \\
\hline 536.993 & 2016.0887 & -97.77205 \\
\hline
\end{tabular}


For an individual running fan, the physical model of the A-frame condenser cell is schematically shown in Figure 2. The windwall and steam duct are taken into consideration. For the fan array, a representative $2 \times 600$ MW direct-dry cooling power plant is investigated. The layout of the ACCs and main buildings, including the boiler, turbine houses and chimney, is schematically shown in Figure 3. Per the typical design data of the power plant, the space between the turbine house and the ACC platform is $12.6 \mathrm{~m}$ and the platform and windwall heights are $45 \mathrm{~m}$ and $12 \mathrm{~m}$, respectively. An air-cooled condenser consists of an array of A-frame condenser cells, each fitted with an axial flow fan as shown in Figure 4. There are two ACCs in this power plant, each having $56(7 \times 8)$ condenser cells. Along the $x$ direction, the left ACC is designated as No. 1, and on the right is No. 2.

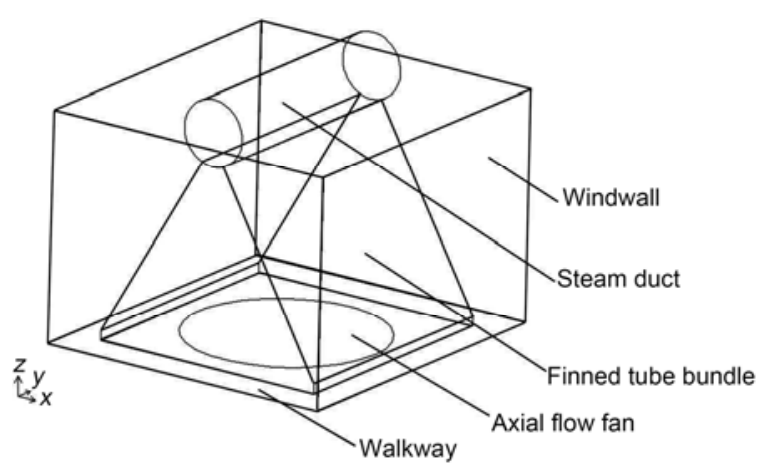

Figure 2 Schematic of condenser cell.

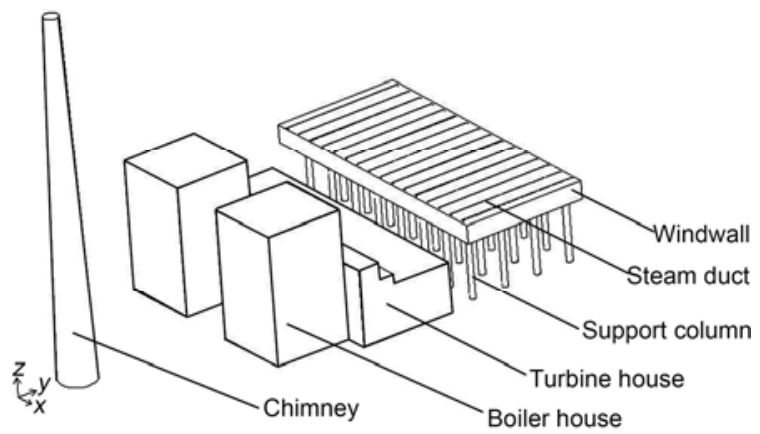

Figure 3 Schematic of ACCs and main buildings in a power plant.

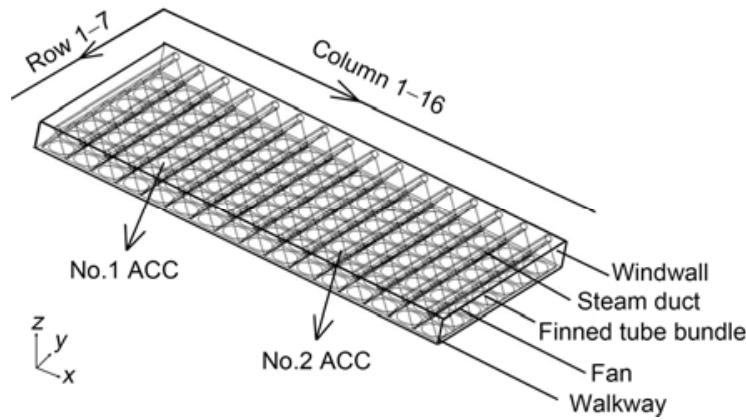

Figure 4 Schematic of condenser cell array and cell serial number specification.
The specification for the condenser cell and fan serial number is also shown.

The aerodynamic behavior of the fan array of with no wind, and with wind at various speeds and directions, is studied. Figure 5 shows the computational domain for these two cases. To eliminate the near-wall effect of the boiler and turbine houses on the flow of cooling air into the ACC, the physical domain of interest should be large enough. Under the no-wind condition, the cylinder volume at the base and the semi-sphere volume at the top form the computational domain, at the center of which the ACCs and main buildings are situated. With non-zero ambient wind, the whole computational domain is represented as a hexahedron. Because of the symmetric structure of the ACCs and main buildings, only half of the wind directions are taken into account (Figure 5(b)). For the central domain with the ACCs and main buildings, a tetrahedral unstructured grid is used. For other zones, a hexahedral structured grid is adopted. After validation of grid independence, the final grid number is about 2125770 for simulation of the fan array of with no wind, and about 2089900 with non-zero ambient wind.

The steady-state fluid and heat flow governing equations on the air-side of the ACCs are as follows [17]:

$$
\begin{gathered}
\frac{\partial\left(\rho u_{i}\right)}{\partial x_{i}}=0, \\
\frac{\partial\left(\rho u_{i} u_{j}\right)}{\partial x_{j}}=\frac{\partial}{\partial x_{j}}\left[\mu_{\mathrm{eff}}\left(\frac{\partial u_{i}}{\partial x_{j}}+\frac{\partial u_{j}}{\partial x_{i}}\right)-\frac{2}{3} \mu_{\mathrm{eff}} \frac{\partial u_{k}}{\partial x_{k}}\right] \\
-\frac{\partial p}{\partial x_{i}}+\rho g_{i}+S_{i}(i, j, k=1,2,3, \text { and } i \neq j), \\
\frac{\partial}{\partial x_{i}}\left(u_{i}(\rho e+p)\right)=\frac{\partial}{\partial x_{i}}\left(\lambda_{\mathrm{eff}} \frac{\partial T}{\partial x_{i}}+u_{j}\left(\tau_{i j}\right)_{\mathrm{eff}}\right)+S_{h},
\end{gathered}
$$

where $u_{i}$ is the velocity in the $x_{i}$ direction, $p$ is the pressure, and $g_{i}$ is the gravitational acceleration in the $x_{i}$ direction. In this model, $g_{i}$ only exists in the $-z$ direction. Because of the large dimension of the A-frame condenser cell and great heat rejection of the exhaust steam, the buoyancy effect of the cooling air is considered and the air is regarded as an incompressible ideal gas. $e=h_{e}-p / \rho+u_{i}{ }^{2} / 2$, is the
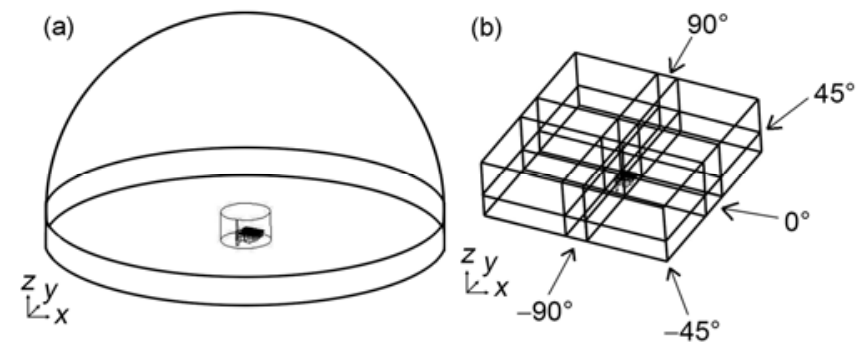

Figure 5 Computational domains including ACCs and main buildings, and characteristic wind direction specifications. (a) With no ambient wind; (b) with ambient wind. 
specific energy, $h_{e}$ is the specific enthalpy. $\mu_{\mathrm{eff}}=\mu+\mu_{t}$, is the effective dynamic viscosity, and $\mu$ and $\mu_{t}$ are the dynamic viscosity and turbulent dynamic viscosity, respectively. $\tau_{\text {eff }}$ is the stress tensor, $\lambda_{\text {eff }}$ is the effective thermal conductivity. $S_{i}$ is the momentum sink and is equal to the pressure drop per flow passage length through the tube bundles. $S_{h}$ is the heat source, namely the heat rejection per volume of the air-cooled condenser.

The standard $k-\varepsilon$ turbulent model is used to describe the flow through the fans and finned tube bundles.

$$
\begin{gathered}
\frac{\partial}{\partial x_{i}}\left(\rho k u_{i}\right)=\frac{\partial}{\partial x_{j}}\left[\left(\mu+\frac{\mu_{t}}{\sigma_{k}}\right) \frac{\partial k}{\partial x_{j}}\right]+G_{K}+G_{b}-\rho \varepsilon, \\
\frac{\partial}{\partial x_{i}}\left(\rho \varepsilon u_{i}\right)=\frac{\partial}{\partial x_{j}}\left[\left(\mu+\frac{\mu_{t}}{\sigma_{\varepsilon}}\right) \frac{\partial \varepsilon}{\partial x_{j}}\right] \\
+C_{1 \varepsilon} \frac{\varepsilon}{k}\left(G_{K}+C_{3 \varepsilon} G_{b}\right)-C_{2 \varepsilon} \rho \frac{\varepsilon^{2}}{k}
\end{gathered}
$$

where $k$ and $\varepsilon$ are the turbulence kinetic energy and its rate of dissipation. $\sigma_{k}$ and $\sigma_{\varepsilon}$ are the turbulent Prandtl number for $k$ and $\varepsilon$, respectively. $C_{1 \varepsilon}, C_{2 \varepsilon}, C_{3 \varepsilon}$ are constants. $G_{k}$ represents the generation of the turbulence kinetic energy arising from mean velocity gradients.

$$
G_{k}=-\rho u_{i} u_{j} \frac{\partial u_{j}}{\partial x_{i}}
$$

$G_{b}$ is the generation of the turbulence kinetic energy by buoyancy. For an ideal gas,

$$
G_{b}=-g_{i} \frac{\mu_{t}}{\rho \operatorname{Pr}_{t}} \frac{\partial \rho}{\partial x_{i}},
$$

where $P r_{t}$ is the turbulent Prandtl number for energy. The model constants have the following default values: $C_{1 \varepsilon}$ $=1.44, C_{2 \varepsilon}=1.92, C_{3 \varepsilon}=1, \sigma_{k}=1.0, \sigma_{\varepsilon}=1.3$.

Under the no-wind condition, the surfaces of the cylinder volume at the base and the semi-sphere volume at the top of the computational domain are assigned pressure inlet and outlet boundaries, respectively. The air temperature at the surfaces of the computational domain is set to $15^{\circ} \mathrm{C}$, which is the usual design ambient temperature for the ACC in China. With non-zero ambient wind, the windward surface at the exterior of the computational domain is the velocity inlet boundary, for which the power-law equation is used to calculate the wind speed at different heights.

$$
u=u_{10}\left(\frac{z}{10}\right)^{m}
$$

where $u_{10}$ is the wind speed at $10 \mathrm{~m}$ height, usually measured by the local weather office. Wind speeds ranging from 3 $\mathrm{m} / \mathrm{s}$ to $15 \mathrm{~m} / \mathrm{s}$ are designated to $u_{10}$ in the present study to investigate the wind effect on the aerodynamic behavior of the fan array. $z$ is the height. The exponent $m$ is related to the roughness of the ground and atmospheric stability. In this paper, $m$ is set equal to 0.2 . The outflow boundary condition is set on the downstream surface. On the other surfaces, symmetry boundaries are designated. The ground is given the adiabatic boundary condition as an approximation. On the surfaces of turbine house, boiler houses and chimney, constant heat flux is assumed. The surfaces of the support column are given approximately adiabatic conditions. The surfaces of the steam duct are given a constant temperature equal to the saturated temperature of the exhaust steam.

The commercial finite volume-based solver Fluent is used to solve eqs. (9)-(13) with the given boundary conditions. The governing equations for momentum and energy are discretized with a finite-volume formulation, using a fully implicit first order upwind differencing scheme. The SIMPLE algorithm is adopted for the pressure-velocity coupling. A divergence-free criterion of $10^{-4}$, based on the scaled residual, is prescribed.

Numerical results are validated by comparing the computed and measured inlet air temperature of a particular condenser cell, as shown in Figure 6. The experiment was conducted in a $4 \times 600 \mathrm{MW}$ direct-dry cooling power plant in the Shaanxi province of China [17]. The modeling and numerical solution methods used in the $4 \times 600 \mathrm{MW}$ power plant simulation are the same as those used for the $2 \times 600$ MW power plant in this paper. The computed and measured inlet air temperatures agree well with each other. Though the computed results show some overestimation, the error is small enough to adequately predict the performance of the fan array and finned tube bundles. The results show that the modeling and numerical methods associated with the air-cooled condensers and main buildings, as well as the fin-tube bundle and fan, are reliable enough for the purposes of this investigation.

\section{Results and discussion}

\subsection{Cluster effect with no wind}

Even under no-wind conditions, fans in the array work interdependently. Figures 7 and 8 give the streamlines of the cooling air at a particular longitudinal and transverse cross section of the computational domain. The figures show that the cooling air in the central air-cooled condenser cells flows through the fan almost vertically. This is similar to an individual fan running. Cooling air at the periphery of the air-cooled condensers flows slantwise through the fan, and inlet flow distortions are clearly visible. The velocity vectors of the swirl flows at the outlet of some fans are shown in Figure 9. The swirl flows of all fans are similar in every detail with no ambient wind.

Volumetric flow rates of individual fans and of all fans in 


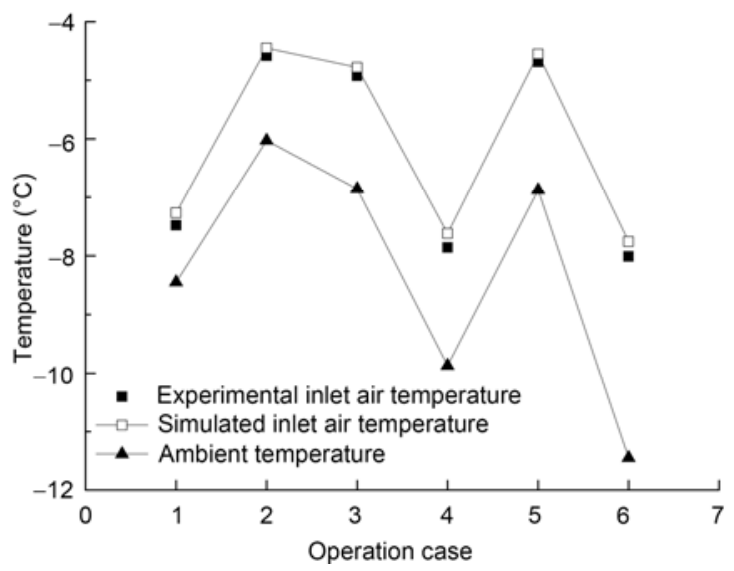

Figure 6 Computed and measured inlet air temperatures of one condenser cell, for some operation cases in a $4 \times 600 \mathrm{MW}$ power plant.

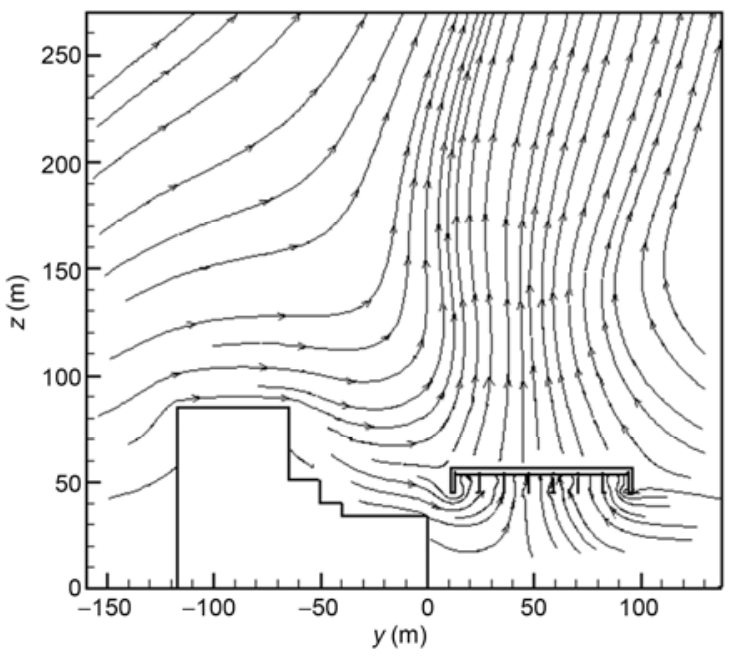

Figure 7 Streamlines at a particular longitudinal cross section containing the main buildings and ACC cells.

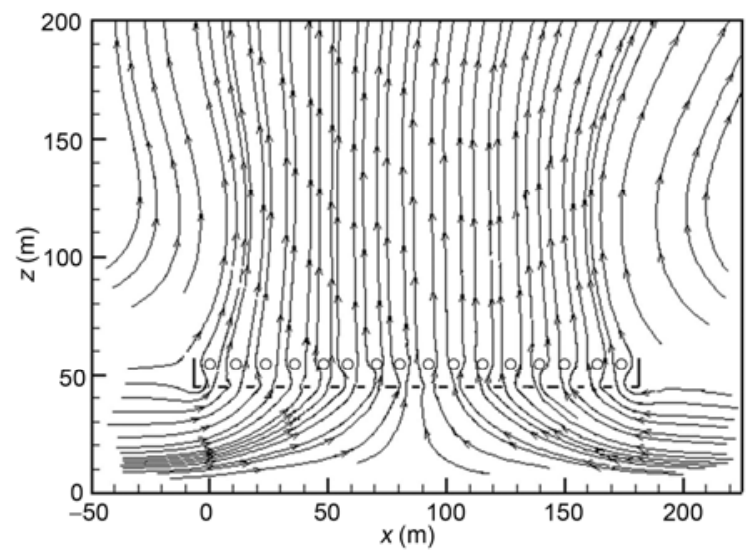

Figure 8 Transverse cross section containing the ACC cells showing streamlines.

the array are all obtained by CFD simulation. The cluster factor of each fan in the condensers is then calculated(shown in Figure 10). The cluster factor differences of

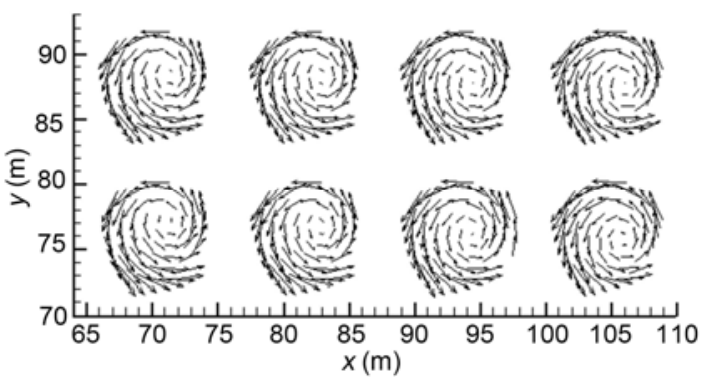

Figure 9 Swirl velocity vectors at some fan outlets, with no ambient wind.

each fan are clearly observed. In general, the fans in the rows 5-7 that are close to the turbine and boiler houses have small cluster factors and, the closer to the buildings, the smaller the cluster factor. This result shows that fans near the main power plant buildings work poorly because of the disadvantageous impacts of the turbine and boiler houses on the inlet flows of the fan. For the fans in the row 1 on the opposite side, the serious inlet flow distortions shown in Figure 7 also result in a reduced cluster factor. Further still, for the fans at the columns 7-10 that are located at the center of the row 1 , the cluster factor reaches its minimum when compared with the fans along the same column. For fans in the middle rows, the cluster factor is relatively high because of the nearly vertical inlet flows shown in Figure 7. For the fans at both sides of the condensers, namely at columns 1 and 16, the cluster factor is lower than that of fans in the same row. This result is from deteriorated inlet flow distortions of the cooling air, as shown in Figure 8. The diverse cluster factors of the array fans show that fans at the periphery of the condensers work poorly owing to serious inlet flow distortions.

\subsection{Cluster effect with ambient wind}

Cross flows at fan inlets induced by ambient wind result in more serious inlet flow distortions. As an example of the cluster effect with ambient wind, Figures 11 and 12 show

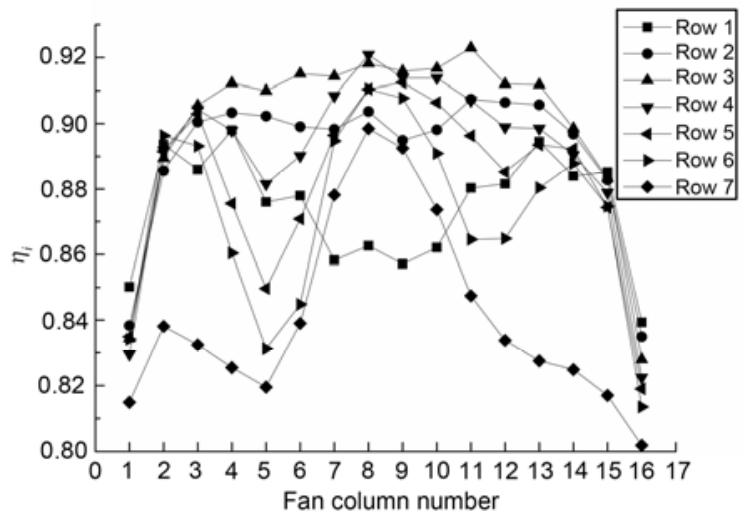

Figure 10 Cluster factor of fans with no ambient wind. 
streamlines at a particular longitudinal and transverse cross section, with a wind speed of $9 \mathrm{~m} / \mathrm{s}$ and characteristic direction of $90^{\circ}$. For the upwind fans facing the ambient wind, the strong cross wind flows inhibit the cooling air flow through them. Furthermore, reversed flows from the finned tube bundle toward the fan may occur, causing a negative flow rate through the fan. This situation is different from hot plume recirculation, in which part of the exit hot air returns to the inlet of the fan, as shown in Figure 12. For the downstream fans, the cross flows from ambient wind are restrained and the cooling air can easily flow through the combined finned tube bundle and fan system. For the transverse cross section across the fans in Row 4, as shown in Figure 12, hot plume recirculation can be observed at both sides of the air-cooled condensers. For other fans in this row, however, there is no plume recirculation and the cooling air easily flows through the fan and finned tube bundle.

The swirl flow fields at the outlet of some fans are shown in Figure 13. In contrast to the swirl flows of fans with no

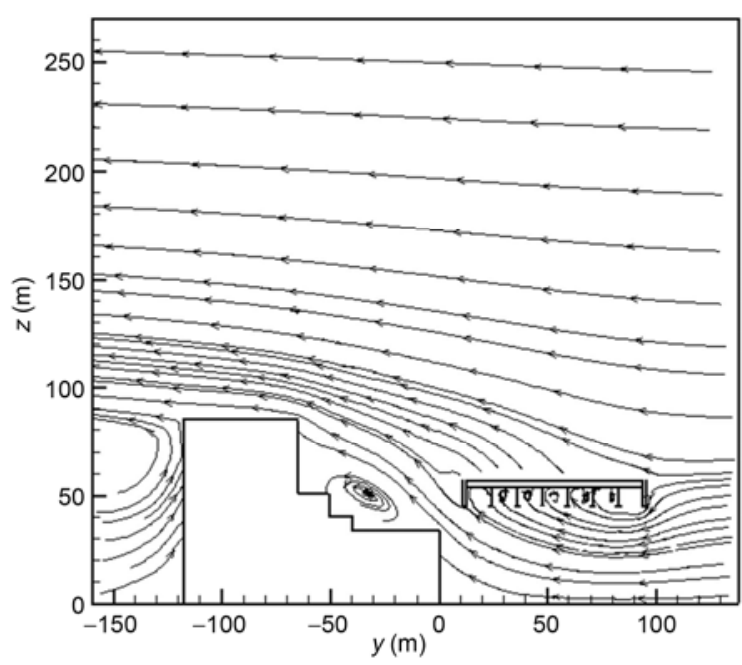

Figure 11 Longitudinal cross section containing the main buildings and ACC cells showing streamlines, with wind speed of $9 \mathrm{~m} / \mathrm{s}$ and characteristic direction of $90^{\circ}$.

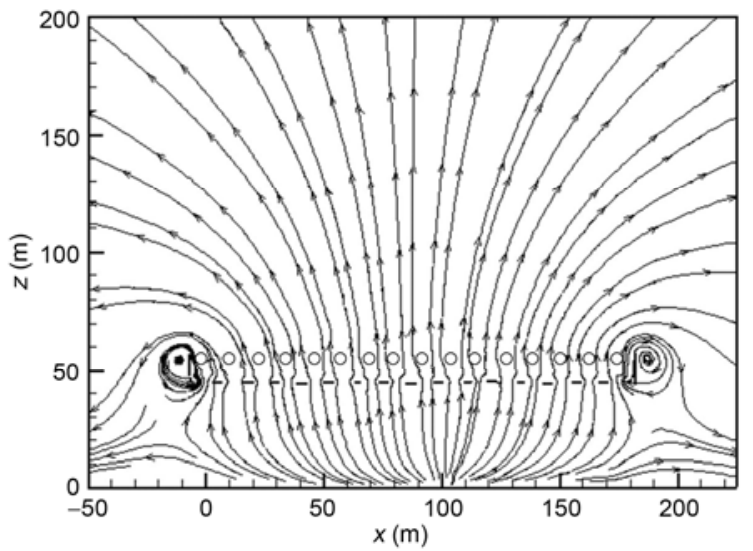

Figure 12 Transverse cross section containing the ACC cells showing streamlines, with wind speed of $9 \mathrm{~m} / \mathrm{s}$ and characteristic direction of $90^{\circ}$.

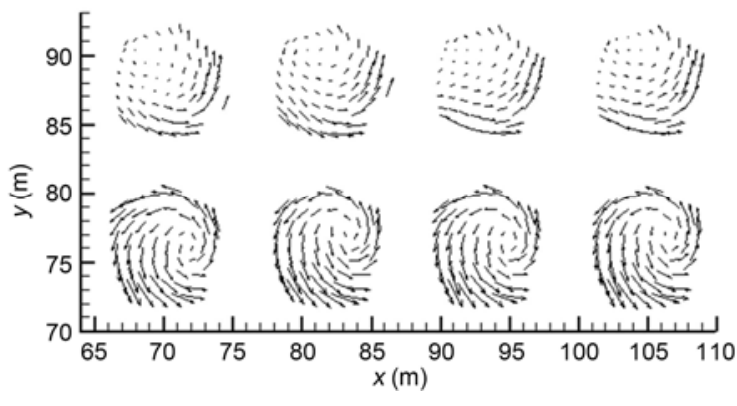

Figure 13 Swirl velocity vectors at some fan outlets, with wind speed of $9 \mathrm{~m} / \mathrm{s}$ and characteristic direction of $90^{\circ}$.

wind, the swirl flow fields of the upwind fans are seriously affected by ambient wind. Reduced tangential velocities for the upwind fans are clearly observed.

Figures 14 and 15 show the cluster factor of the fan at a wind speed of $9 \mathrm{~m} / \mathrm{s}$ and characteristic wind directions of $90^{\circ}$ and $-90^{\circ}$, respectively. Because of the cluster effect of the fan array, the cluster factor of each fan varies widely from each other. At the $9 \mathrm{~m} / \mathrm{s}$ wind speed and $90^{\circ}$ characteristic direction, the cluster factor of upwind fans is lower than that of downstream fans. For some of the fans in Row 1

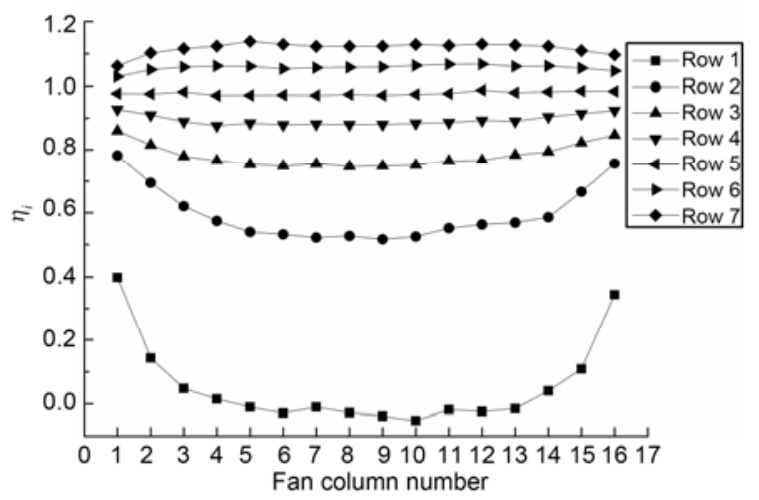

Figure 14 Cluster factor of fans with wind speed of $9 \mathrm{~m} / \mathrm{s}$ and characteristic wind direction of $90^{\circ}$.

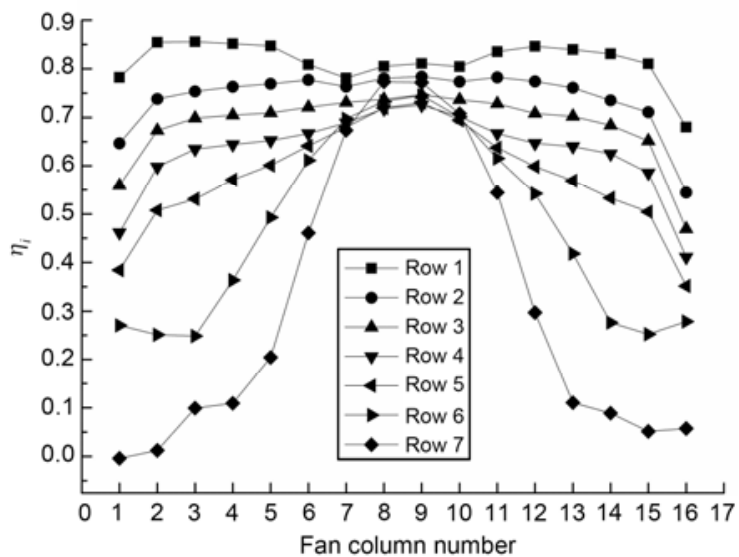

Figure 15 Cluster factor of fans with wind speed of $9 \mathrm{~m} / \mathrm{s}$ and characteristic wind direction of $-90^{\circ}$. 
facing the ambient wind, the cluster factor is even negative. This finding shows that the cluster effect for fans facing the ambient wind is serious, and the resulting deterioration of fan performance is unfavorable to the thermal characteristics of the finned tube bundles. Except for the fans facing the wind, the cluster factor of other fans is comparatively high. The wind direction of $90^{\circ}$ is relatively beneficial to fan array performance. At the characteristic wind direction of $-90^{\circ}$, the cluster factor of upwind fans is also lower than that of downstream fans, with a similar distribution as that with the $90^{\circ}$ characteristic direction. For fans in the same row at both sides, the cluster factor is lower than that of fans in the central part, except for fans in the Row 1. This result stems from the serious inlet flow distortions for the fans at both sides of the condensers.

When the volumetric flow rate of each fan in the array is obtained, the average cluster factor can be calculated according to eq. (2). Variations of the average cluster factor of fans with wind speed and direction are shown in Figure 16, which illustrates that the average cluster factor varies widely with wind speed and direction. The average cluster factor decreases dramatically with increasing wind speed. For example, at a characteristic wind direction of $-90^{\circ}$, the average cluster factor decreases from 0.81 at a wind speed of $3 \mathrm{~m} / \mathrm{s}$ to 0.52 at a wind speed of $15 \mathrm{~m} / \mathrm{s}$, a decrease of about $36 \%$. The cluster effect of fans is most serious at a wind direction of $-90^{\circ}$, indicating that ambient wind blowing from the boiler and turbine houses toward the air-cooled condensers is most disadvantageous to fan operation. When designing the layout of the ACCs and main buildings of the power plant, this prevailing wind direction should be avoided. At wind speeds under $9 \mathrm{~m} / \mathrm{s}$, the average cluster factor reaches its maximum at a wind direction of $0^{\circ}$. However, at wind speeds greater than $9 \mathrm{~m} / \mathrm{s}$, the wind direction of $90^{\circ}$ is most favorable to fan performance. Optimization of the design and operation of the axial flow fans for air-cooled condensers is aided by detailed inquiry into cluster factor variation with ambient wind.



Figure 16 Average cluster factor of fans versus wind speed and characteristic wind direction.

\section{Conclusions}

The cluster effect of the axial flow fan array used by air-cooled condensers in a power plant is investigated, through simultaneous resolution of the thermal-flow characteristics of the combined finned tube bundles and fan system.

With no ambient wind, inlet flow distortions of fans at the periphery of the air-cooled condensers result in poor fan performance and reduced flow rate of cooling air. The near-wall impacts of the turbine and boiler houses on the inlet flows of fans also reduces fan performance. The swirl flows of all fans in the array are nearly the same under no-wind conditions.

With ambient wind, the cluster factors of upwind fans are generally lower than those of downstream ones. The cluster effect for fans facing the ambient wind is most serious. The average cluster factor varies widely with wind speed and direction. The average cluster factor falls dramatically with increasing wind speed. The ambient wind blowing from the boiler and turbine houses toward the air-cooled condensers is most unfavorable to fan performance. At wind speeds less than $9 \mathrm{~m} / \mathrm{s}$, the average cluster factor is maximized at a wind direction of $0^{\circ}$. However, at wind speeds greater than $9 \mathrm{~m} / \mathrm{s}$, a $90^{\circ}$ wind direction is most beneficial to the fans.

This work was supported by the National Basic Research Program of China (2009CB219804) and the National Key Technology R\&D Program of China (2011BAA04B02).

1 Tawney R, Khan Z, Zachary J. Economic and performance evaluation of heat sink options in combined cycle applications. J Eng Gas Turbines Power, 2005, 127: 397-403

2 Meyer C J, Kroger D G. Numerical simulation of the flow field in the vicinity of an axial flow fan. Int J Numer Meth Fluids, 2001, 36: 947-969

3 Meyer C J. Numerical investigation of the effect of inlet flow distortions on forced draught air-cooled heat exchanger performance. Appl Therm Eng, 2005, 25: 1634-1649

4 Hotchkiss P J, Meyer C J, von Backstrom T W. Numerical investigation into the effect of cross-flow on the performance of axial flow fans in forced draught air-cooled heat exchangers. Appl Therm Eng, 2006, 26: 200-208

5 van Rooyen J A, Kroger D G. Performance trends of an air-cooled steam condenser under windy conditions. J Eng Gas Turbines Power, 2008, 130: 023006

6 Bredell J R, Kroger D G, Thiart G D. Numerical investigation into aerodynamic blade loading in large axial flow fans operating under distorted inflow conditions. Res Dev J, 2006, 22: 11-17

7 Coetzeet R V, du Toit C G. Numerical modeling of an air-cooled heat exchanger: influence of end-effects on results. Res Dev J, 2004, 20: 16-23

8 Meyer C J, Kroger D G. Numerical investigation of the effect of fan performance on forced draught air-cooled heat exchanger plenum chamber aerodynamic behavior. Appl Therm Eng, 2004, 24: 359-371

9 Bredell J R, Kroger D G, Thiart G D. Numerical investigation of fan performance in a forced draft air-cooled steam condenser. Appl Therm Eng, 2006, 26: 846-852

10 Duvenhage K, Kroger D G. The influence of wind on the performance of forced draught air-cooled heat exchangers. J Wind Eng Ind 
Aero, 1996, 62: 259-277

11 Duvenhage K, Vermeulen J A, Meyer C J, et al. Flow distortions at the fan inlet of forced-draught air-cooled heat exchangers. Appl Therm Eng, 1996, 16: 741-752

12 Salta C A, Kroger D G. Effect of inlet flow distortions on fan performance in forced draught air-cooled heat exchangers. Heat Recovery Systems CHP, 1995, 15: 555-561

13 Meyer C J, Kroger D G. Plenum chamber flow losses in forced draught air-cooled heat exchangers. Appl Therm Eng, 1998, 18: 875-893

14 Meyer C J, Kroger D G. Air-cooled heat exchanger inlet flow losses.
Appl Therm Eng, 2001, 21: 771-786

15 Wang Q W, Zhang D J, Zeng M, et al. CFD simulation on a thermal power plant with air-cooled heat exchanger system in north China Author. Eng Comp, 2008, 25: 342-365

16 Yang L J, Du X Z, Yang Y P, et al. Operation performance analysis of axial flow fan cluster in direct air-cooled system (in Chinese). In: Proceedings of the CSEE, 2009, 29: 1-5

17 Yang L J, Du X Z, Yang Y P. Measures against the adverse impact of natural wind on air-cooled condensers in power plant. Sci China Technol Sci, 2010, 53: 1320-1327

Open Access This article is distributed under the terms of the Creative Commons Attribution License which permits any use, distribution, and reproduction in any medium, provided the original author(s) and source are credited. 